\title{
5 Gastroenterological Problems of HIV Infection and AIDS
}

Ian McGowan and Duncan Churchill

\section{Introduction}

Gastrointestinal disease oscurs in the majority of patients with the acquired immunodeficiency syndrome (AIDS). Opportunistic gut infection and neoplasia occur throughout the gut. The differential diagnosis of HIV-related gastrointestinal symptoms is large and includes tumours and a variety of opportunistic infections. Multiple pathology is common. Investigation of gastrointestinal symptoms is important as many pathogens will respond to specific therapy, although relapse is common and long-term treatment may be necessary. Where specific treatment for gastrointestinal disease is not available or has been unsuccessful it is always possible to palliate patients' symptoms and improve their quality of life. This chapter aims to describe some of the more common gastrointestinal problems that physicians are likely to encounter and to provide guidelines for investigation and management.

\section{Presentation of Gastroenterological Problems}

\section{Oral Lesions}

Oral disease is common in patients with HIV infection and AIDS. It is important to recognise the presence of oral disease for three reasons. Firstly, it may be the cause of treatable symptoms. Secondly, the nature of lesions seen in the mouth may suggest the nature of disease elsewhere in the gut (e.g., oral herpes and candida may be associated with similar lesions in the oesophagus). Thirdly, some oral lesions such as oral hairy leukoplakia and oral candidiasis are important prognostic markers.

The commonest oral disease seen is candidiasis. In the pseudomembranous form, white plaques are seen on the mucosa of the mouth (Fig. 5.1). The appearance is characteristic, and diagnosis is usually straightforward. An atrophic form of oral candidiasis is also encountered, with smooth red patches on the palate, tongue, or buccal mucosa. This is often missed without careful examination. Oral candidiasis is an important marker of disease progression: in a cohort of 
Fig. 5.1. Oral candidiasis.
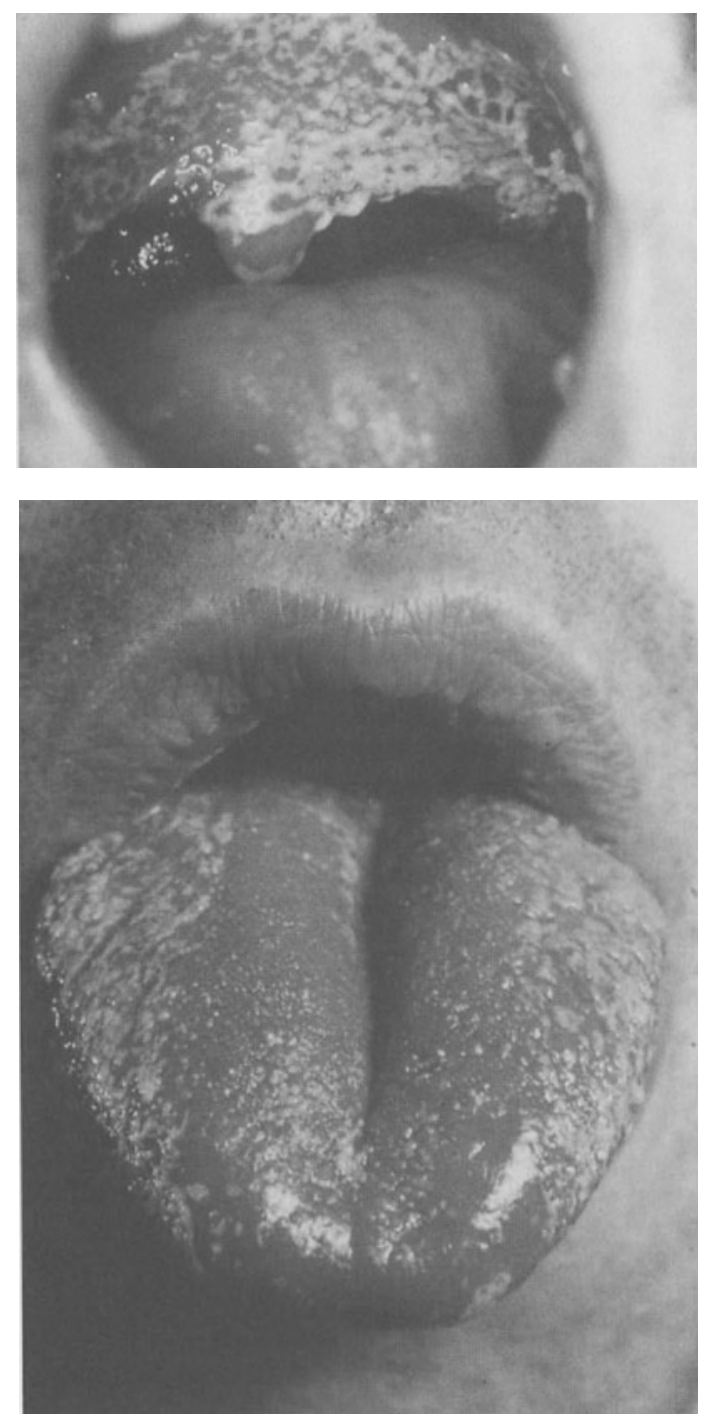

seropositive homosexual men in London, $50 \%$ progressed to AIDS within a year of the onset of oral candidiasis (Kelly et al. 1990). In an American series 59\% of HIV-positive patients with pseudomembranous candidiasis developed AIDS within 3 months of diagnosis (Klein et al. 1984). Candidiasis commonly causes oral discomfort, and although it may initially respond to topical therapy, the majority of patients will require systemic therapy (Table 5.4).

Oral hairy leukoplakia is another characteristic lesion seen in patients with HIV. It is recognised as ribbed white areas on the lateral part of the tongue, or less commonly on the buccal mucosa or dorsum of the tongue (Fig. 5.2). It is due to infection with Epstein-Barr virus (EBV) (Greenspan et al. 1985). In homosex- 


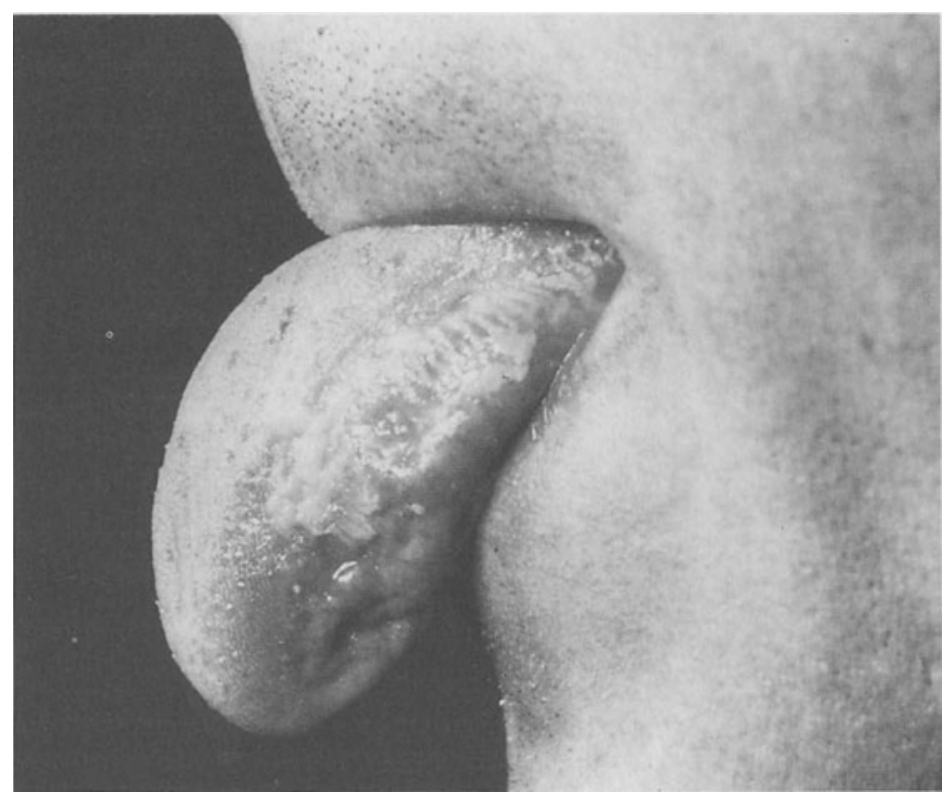

Fig. 5.2. Oral hairy leukoplakia.

ual men oral hairy leukoplakia is associated with a risk of approximately $40 \%$ of progression to AIDS within one year (Kelly et al. 1990). It is usually asymptomatic, but if particularly painful can be treated with acyclovir (Resnick et al. 1988).

Kaposi's sarcoma (KS) can occur anywhere in the mouth, and is often associated with cutaneous KS. In particular palatal KS is strongly associated with visceral disease. Radiotherapy is effective treatment for symptomatic or unsightly local lesions, but may produce severe mucositis (Watkins et al. 1989).

The differential diagnosis of oral ulceration in HIV disease is wide. Examination of the mucosa can give clues to the cause of the ulceration, but additional investigations are needed to confirm the diagnosis. Infection with Herpes simplex virus (HSV) presents with crops of small, painful, vesicular ulcers on the fauces or palate, and may be associated with circumoral ulcers. The diagnosis can be confirmed by viral culture. Cytomegalovirus (CMV) infection is less common in the mouth, and causes isolated ulcers. Viral culture is unhelpful, as this virus is frequently shed from the mucosal surfaces of asymptomatic patients with HIV infection (Quinnan et al. 1984). Biopsy may reveal characteristic histopathological features of CMV infection. Oro-pharyngeal ulceration not associated with HSV or CMV is usually classified as aphthous ulceration; however, controversy exists as to whether this form of ulceration should more correctly be called HIV-associated ulceration. If there is no response to treatment for HSV or aphthous ulceration, biopsy should be considered to exclude CMV and lymphoma, which are rarer causes of mucosal ulceration.

Oral warts, due to infection with human papilloma virus (HPV), are seen on occasion on the buccal mucosa of patients with HIV. Xerostomia, the sensation 
of a dry mouth, may also be remarked on by patients. There is usually no clear underlying cause. The treatment of these conditions is outlined below.

\title{
Oesophageal Symptoms
}

At least $10 \%$ of all patients with HIV infection will experience oesophageal symptoms at some stage of their illness (Fauci et al. 1984) (Table 5.1). Symptoms include pain on swallowing both solids and liquids, or a sensation of food sticking in the oesophagus. Some patients also describe epigastric or retrosternal pain unrelated to swallowing. (The causes of oesophageal symptoms are listed in Table 5.1). The combination of oral candidiasis and oesophageal symptoms is highly predictive of oesophageal candidiasis (Tavitian et al. 1986; Connolly et al. 1989a), and this underlies the practice of giving empirical treatment with antifungal drugs, without further investigation.

Oesophageal candidiasis causes odynophagia, or pain on swallowing, although it may be clinically silent (Clotet et al. 1986). It is almost always associated with oral candidiasis, but may also be seen in association with other oesophageal pathology (Laine et al. 1992a). It has a characteristic endoscopic appearance, with white plaques in the distal oesophagus (Fig. 5.3) or a white membrane extending circumferentially around the oesophageal mucosa. Biopsies are not usually needed but may be helpful if there is doubt about the diagnosis. Treatment is with systemic antifungal agents.

In patients with oesophageal symptoms but without oral candidiasis, those who fail to respond to antifungal treatment, and those without an AIDS diagnosis, endoscopy supplemented by biopsy is the investigation of choice. Barium swallows have an inferior sensitivity, especially for oesophageal candidiasis, and lack specificity in the diagnosis of oesophageal ulceration (Connolly et al. 1989b).

Cytomegalovirus (CMV) is a less common cause of oesophageal pathology (Jacobson et al. 1988; Wilcox et al. 1990). Characteristically it produces large shallow ulcers in the distal oesophagus, although other presentations include lesions in the mid and upper oesophagus, multiple small ulcers throughout the oesophagus and diffuse oesophagitis. Evidence of CMV infection at other sites is seen in a minority of patients. The diagnosis must be confirmed by endoscopic biopsy. Large intranuclear inclusions are seen on haematoxylin and eosin (H\&E)

Table 5.1. Causes of oesophageal symptoms in patients with AIDS

\author{
Candida \\ Cytomegalovirus \\ Herpes simplex virus \\ Epstein-Barr virus \\ Aphthous ulceration \\ Mycobacterium avium intracellulare \\ Cryptosporidium \\ Kaposi's sarcoma \\ Non-Hodgkin's lymphoma \\ Peptic oesophagitis \\ Primary HIV seroconversion illness
}




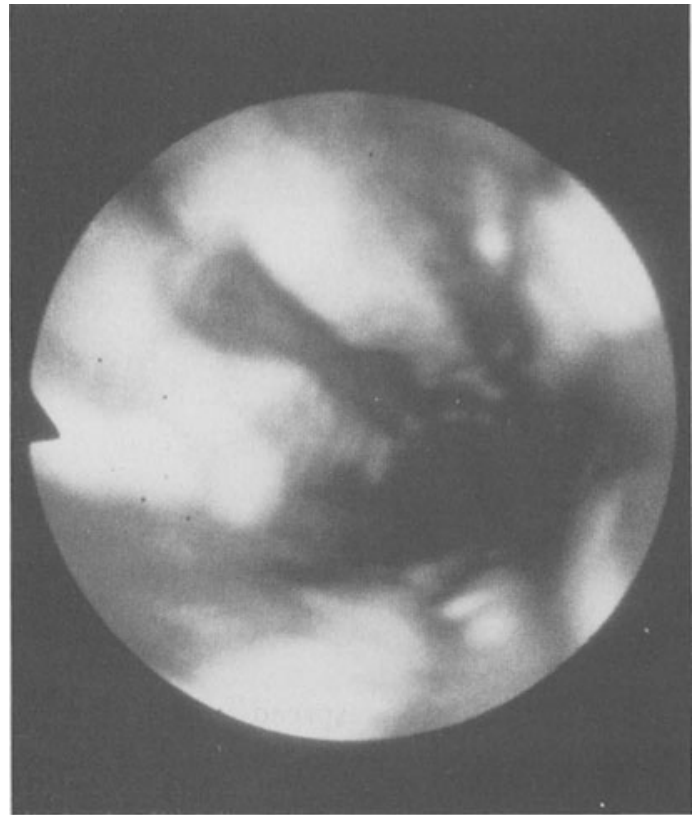

Fig. 5.3. Endoscopic view of oesophageal candidiasis.

staining of biopsy specimens, predominantly in endothelial cells in the submucosa (Weber et al. 1987). Immunohistochemical staining can be helpful if H\&E staining of a suspicious ulcer is negative (Francis et al. 1989; Theise et al. 1991). CMV oesophagitis usually develops late in the course of HIV infection; most patients have had an AIDS diagnosis by the time they develop CMV oesophagitis. The prognosis is consequently poor, with a median survival of 4-6 months from the time of diagnosis (Wilcox et al. 1990).

Herpes simplex oesophagitis is usually accompanied by oral herpes, and produces multiple superficial, fluid-filled vesicles or shallow ulcers. Biopsies show characteristic multinucleated cells.

A syndrome of acute symptomatic oesophageal ulceration complicating HIV seroconversion has been described (Rabenek et al. 1990). Oesophageal symptoms are accompanied by malaise, fever, myalgia, and often a macular rash. Endoscopy shows single or multiple small oesophageal ulcers with characteristic histological changes seen on light microscopy. Under electron microscopy, HIVlike particles can be seen in the mucosa. The ulceration heals spontaneously without treatment. On occasion, oesophageal candidiasis may complicate seroconversion, but this also heals without treatment.

EBV has been recognised as a cause of oesophageal ulceration in patients with HIV infection (Kitchen et al. 1990). There are macroscopic similarities with aphthous ulcers, but biopsies show specific histological features which resemble those seen in oral hairy leukoplakia, with EBV detected in tissue from these ulcers by in-situ hybridisation (Kitchen et al. 1990). The ulcers may be endoscopically distinguishable from CMV- and HSV-associated ulcers, and are said to be deep, linear, and usually in the mid oesophagus. Similar lesions can be found in the pharynx in some patients, although interestingly no association with oral hairy leukoplakia has been reported. 
Other, less common, causes of oesophageal symptoms in HIV infection include oesophageal cryptosporidiosis (Kazlow et al. 1986), and Mycobacterium avium-intracellulare (Grayand Rabenek 1989). Non-Hodgkin's lymphoma may affect the oesophagus. Kaposi's sarcoma of the oesophagus does not usually cause symptoms, unless there is associated mucosal ulceration.

\section{Abdominal Pain}

The differential diagnosis of abdominal pain in patients with HIV infection is similar to that in patients without HIV infection, but specific diagnoses including extensive visceral KS, CMV ulceration affecting the oesophagus, stomach or duodenum, mesenteric adenopathy, and AIDS sclerosing cholangitis (ASC) should also be considered.

\section{Gastrointestinal Bleeding}

This is an uncommon problem, perhaps due to the widespread empirical use of $\mathrm{H}_{2}$ receptor antagonists. Non-Hodgkin's lymphoma, KS and CMV disease may all cause gastrointestinal haemorrhage. Patients with thrombocytopenia are at increased risk of bleeding (Parente et al. 1991).

\section{Jaundice}

Frank jaundice is rarely seen in association with HIV disease. Homosexual men and injecting drug users are still the most common groups infected with HIV in Europe, and viral hepatitis and the late sequelae of chronic viral hepatitis are the most common causes of jaundice. Occasionally jaundice is seen in patients with AIDS sclerosing cholangitis (Cello 1989) or secondary to drugs (Table 5.5). Patients may be asymptomatic, or present with fever, abdominal pain or hepatomegaly.

\section{Weight Loss/Anorexia}

Weight loss is a major problem in AIDS and directly influences survival (Kotler et al. 1989a). The causes of weight loss are multifactorial and include anorexia, malabsorption, and chronic diarrhoea. In addition disturbance of cytokine production associated with opportunistic infections such as tuberculosis may contribute to further weight loss. "Enteropathic" AIDS is a more extreme form seen in Africa, where it is known as "slim disease" (Serwadda et al. 1985). Patients may complain specifically of weight loss, or more commonly clinicians notice a gradual decline in body mass in patients attending clinic.

\section{Diarrhoea}

Diarrhoea is a significant problem in $50 \%-90 \%$ of HIV patients. The differential diagnosis is very wide (Table 5.2). Patients may only complain of diarrhoea, or 
Table 5.2. Pathogens in HIV associated diarrhoea

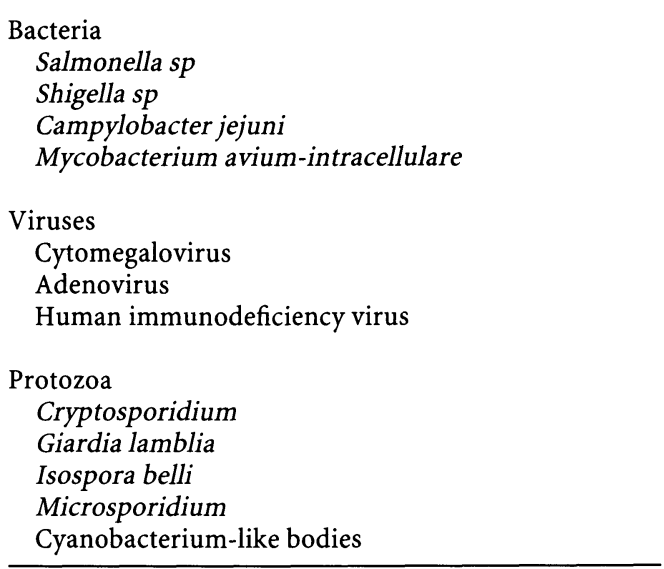

may have other symptoms such as fever, weight loss, or abdominal pain. A careful history may not elucidate the cause of the diarrhoea, but it may provide clues as to the site of infection and will enable the clinician to assess the severity of the problem. Cramps, bloating and nausea suggest small intestinal or gastric pathology. Haematochezia points towards colonic disease, whilst tenesmus is associated with proctitis or a rectal lesion.

\section{Perianal Problems}

Anorectal disease is particularly common in sexually active homosexual men, and so may be found in association with HIV disease. Some of the causes are listed in Table 5.3, and all male homosexual patients presenting with anorectal symptoms such as irritation, itching, pain, or rectal discharge should be screened for sexually transmitted infections. Clinical examination with proctoscopy is important, but specific diagnosis depends on microbiological confirmation.

\section{Kaposi's Sarcoma/Lymphoma}

Kaposi's sarcoma (KS) is the commonest tumour associated with HIV infection, and is commonly seen in the gastrointestinal tract. In a series from San Francisco, KS was found at post mortem in the gut of $70 \%$ of patients dying of AIDS (Friedman et al. 1985). KS is commoner in homosexual men and patients from developing countries than in patients from other risk groups, and it has been suggested that another sexually transmitted agent may be involved in the pathogenesis of KS (Beral et al. 1990, 1991). In the majority of patients, gastrointestinal KS is asymptomatic; however, it may be the cause of bleeding, obstruction, perforation, and protein-losing enteropathy (Perrone et al. 1981). The presence of gastrointestinal KS should be considered if there is cutaneous or palatal disease. Diagnosis is by endoscopy; the lesions are characteristic, but it is prudent to take biopsies for histological confirmation. 
Table 5.3. Causes of ano rectal symptoms in HIV disease

\begin{tabular}{l} 
Bacteria \\
Chlamydia trachomatis \\
Neisseria gonorrhoeae \\
Treponema pallidum \\
Viruses \\
Herpes simplex \\
Cytomegalovirus \\
Human papilloma virus \\
Neoplasia \\
Lymphoma \\
Kaposi's sarcoma \\
Anal carcinoma \\
\hline
\end{tabular}

Lymphoma is much less common than KS. With the advent of effective prophylaxis against common opportunistic infections such as Pneumocystis, patients are surviving longer, and the incidence of lymphoma is increasing. HIVassociated lymphomas are usually high grade non-Hodgkin's type of B-cell origin (Knowles et al. 1988; Pluda et al. 1990). Extranodal involvement is typical and the gut is the commonest site involved.

\section{Investigation of Gastroenterological Problems}

\section{Stool Culture and Microscopy}

The differential diagnosis of HIV-associated diarrhoea includes many unusual organisms (Table 5.2), and in addition more common organisms such as Salmonella species may present atypically with septicaemia or disseminated infection (Nelson et al. 1992)

Diarrhoea lasting in excess of 2 weeks warrants investigation. Stool samples should be collected and sent for routine culture, parasitological examination, and culture for Mycobacteria. It is important that the laboratory is notified of the patient's HIV seropositivity since examination for organisms such as Cryptosporidium may not otherwise be carried out. Identifying the oocysts of Cryptosporidium remains difficult. The organism is small $(4.5 \mu \mathrm{m})$, and may be shed intermittently. Ma and colleagues have described a three-stage examination to improve the diagnostic yield (Ma and Soave 1983), but most laboratories use a modified Ziehl-Neelsen technique as a screening test. Concentration techniques such as Sheather's sugar flotation method (Sheather 1953) may be helpful in follow-up of patients excreting small numbers of oocysts. Monoclonal antibodies directed against oocyst wall antigens are now available and may in the future become a routine test to identify Cryptosporidium in faecal smears.

Pathogen-negative diarrhoea (PND) is a difficult clinical problem in patients with HIV disease. PND is diagnosed on the basis of 6 negative stool examinations together with a normal rectal biopsy (Connolly et al. 1989c). Upper gastrointestinal endoscopy with microscopic examination of duodenal aspirate and 
mucosa is sometimes helpful in patients with PND. Histopathological examination of duodenal tissue may show evidence of colonisation with organisms such as Cryptosporidium (Fig. 5.4). Greenson et al. (1991) showed that when conventional laboratory practice was augmented by examination of duodenal mucosal biopsies with light and electron microscopy, it was possible to identify pathogens in $11 / 22$ patients with PND. The organisms most commonly identified by electron microscopy were Microsporidia, thought to be Enterocytozoon bienusi. Stool samples and duodenal smears stained with Giemsa are being evaluated for use in identifying Microsporidium (Van Gool et al. 1990; Weber et al. 1992).

Antibiotic-associated diarrhoea, including pseudomembranous colitis due to Clostridium difficile is occasionally seen in patients with HIV infection. It is important to look for $C$. difficile toxin in the stools of patients whose diarrhoea is otherwise unexplained.

\section{Radiology/Ultrasound}

Plain abdominal radiographs have a limited role in the investigation of HIVrelated abdominal symptoms. They can demonstrate the presence of renal calculi (if radiopaque), calcification associated with chronic pancreatitis, or gas under the diaphragm associated with a perforated viscus. In patients with diarrhoea and abdominal pain, a plain radiograph may show toxic dilatation of the bowel, or conversely may establish that the diarrhoea is in fact due to faecal impaction with overflow.

Double contrast barium studies lack sensitivity and specificity and are rarely performed in AIDS patients. A study comparing endoscopy with double

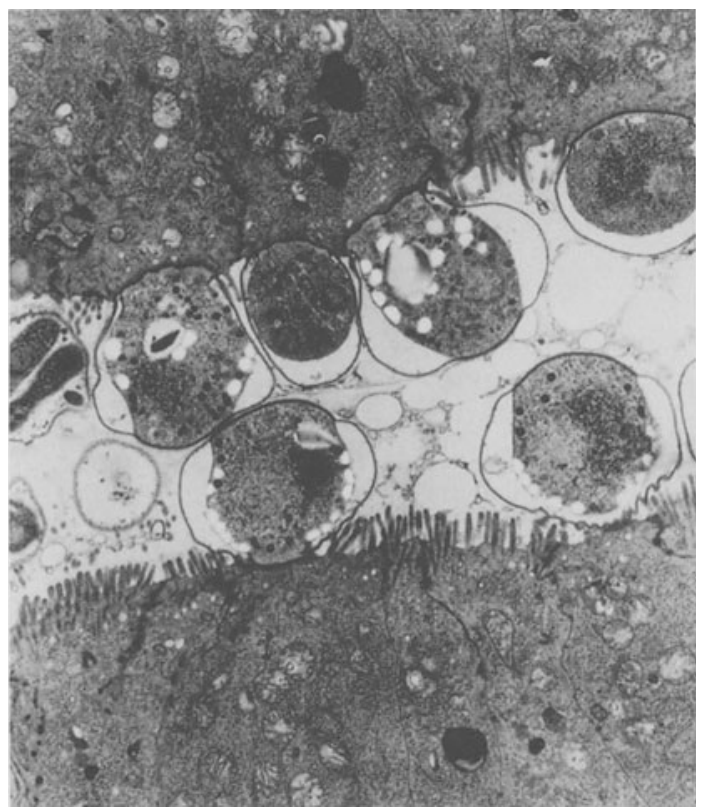

Fig. 5.4. Electron micrograph of Cryptosporidium oocysts attached to small bowel surface epithelium cells from a patient with chronic diarrhoea. 
contrast barium examination in the investigation of upper gastrointestinal symptoms in AIDS patients showed that endoscopy combined with appropriate microbiological and histological sampling provided the correct diagnosis in $95.5 \%$ of cases, compared with $31 \%$ from barium studies (Connolly et al. 1989a).

Ultrasound is most useful in imaging the biliary tree, examining intraabdominal lymph nodes, looking for ascites, and directing percutaneous biopsies.

\section{Endoscopy}

Fibre-optic endoscopy is of considerable value in investigating HIV-positive patients with gastroenterological complaints. It is especially useful in patients with oesophageal symptoms, most of whom will have a diagnosis made after a single investigation. Endoscopy with biopsy of the duodenum and duodenal aspiration has a role in the investigation of diarrhoea. Other indications for upper gastrointestinal endoscopy include the assessment of gastrointestinal KS, and the investigation of abdominal pain. Peptic ulcers should always be biopsied, as CMV may cause ulceration throughout the gastrointestinal tract.

Sclerosing cholangitis has been found to occur in patients with HIV. The aetiology remains uncertain, but there is a strong association with Cryptosporidium and CMV (Cello 1989). Patients present with right upper quadrant pain, elevated alkaline phosphatase, and occasionally fever. There is a characteristic beading and variable stenosis of the biliary tree, which becomes more marked as the disease progresses (Fig. 5.5). These changes may be seen with ultrasound examination, but ERCP is probably more sensitive. There is some evidence that the pain associated with AIDS sclerosing cholangitis (ASC) may be improved by performing an endoscopic sphincterotomy (Dowsett et al. 1988; Schneiderman et al. 1987), and it is probably this group of patients who should be investigated with ERCP.

In the investigation of patients with diarrhoea, repeated stool examinations and rigid sigmoidoscopy with rectal biopsy are the most helpful procedures (Connolly et al. 1989c). The roles of flexible sigmoidoscopy and colonoscopy are less well defined but are the only way to diagnose proximal CMV colitis/ileitis.

It is important to take multiple biopsies from any lesion seen at endoscopy. When taking biopsies from oesophageal ulcers, it is usually easiest to biopsy the edge of the ulcer rather than the base. Deep biopsies are needed if Kaposi's sarcoma or CMV are suspected, as there is a high false-negative rate. This is due to the submucosal situation of KS lesions and the cells infected with CMV (Friedman et al. 1985; Connolly et al. 1989b; Theise et al. 1991). CMV cultures from ulcer biopsies are unhelpful as CMV viraemia is seen in up to $50 \%$ of patients with AIDS (Quinnan et al. 1984). Some patients with immunohistochemically proven CMV ulceration may have negative cultures (Wilcox et al. 1990). The diagnosis depends on histological demonstration of CMV inclusion bodies.

Brush cytology of lesions seen at endoscopy may help to increase the yield. Saline washes of the cytology brush have been shown to be a sensitive method of diagnosing oesophageal. Candida (Connolly et al. 1989a) but this is not usually needed. 


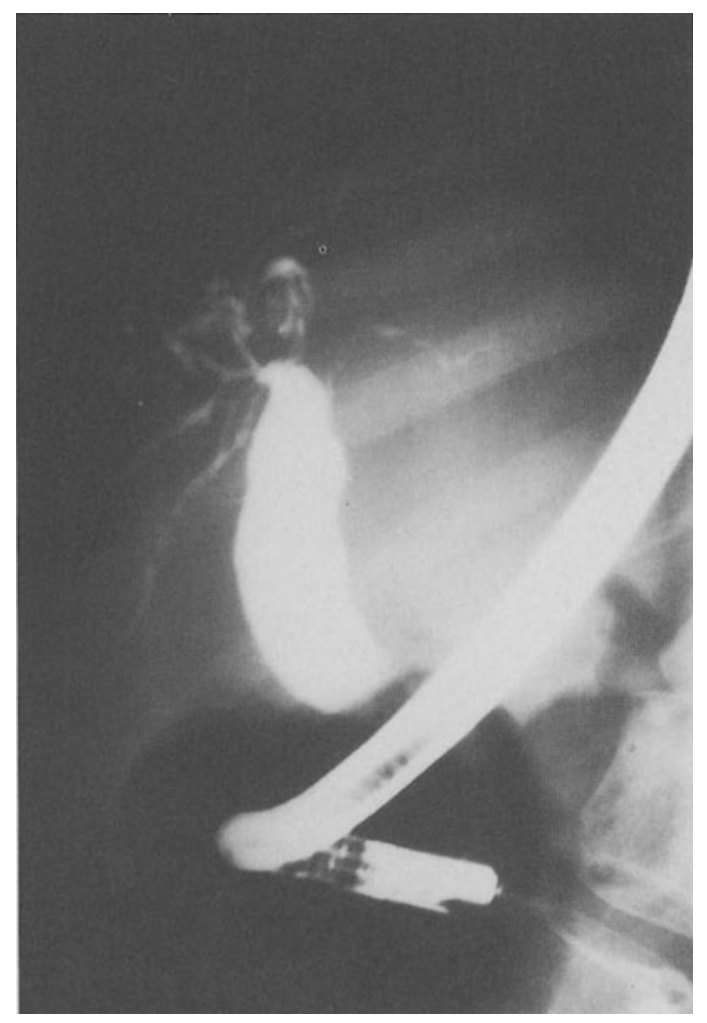

Fig. 5.5. ERCP study showing widespread stricturing of intrahepatic biliary tree in a patient with AIDS sclerosing cholangitis.

All patients undergoing endoscopy should be treated as being potentially HIV positive, and appropriate care taken to avoid the risk to staff (British Society of Gastroenterology Working Party Report 1989). Manual cleaning of endoscopes is the most important step in ensuring sterilisation of the instruments after procedures. Following thorough manual cleaning, the majority of pathogens (including HIV) are inactivated by a 4 -minute soak in $2 \%$ glutaraldehyde. Procedures on patients who are immunosuppressed, including those with HIV infection, should be carried out after a 1-hour soak of the instrument in $2 \%$ glutaraldehyde, in order to ensure inactivation of more persistent organisms including Mycobacteria and Cryptosporidium. Dedicated instruments are not needed.

\section{Nuclear Medicine}

${ }^{99} \mathrm{~m} \mathrm{Tc}$-Iminodiacetic acid scans of the liver and biliary tree may be of use in the diagnosis of ASC, especially in early cases where ultrasound and/or CT scans of the abdomen have failed to give a precise diagnosis or to demonstrate dilatation of the biliary tree (Fig. 5.6). This method has a high sensitivity in the detection of abnormality in the biliary tree (Miller et al. 1990), and is useful in deciding which patients should be referred for ERCP. 
Fig. 5.6. Serial ${ }^{99 \mathrm{~m}}$ Tc-iminodiacetic acid scans of the liver, showing marked delay in excretion of tracer from the intrahepatic biliary tract and common bile duct in a patient with AIDS sclerosing cholangitis.

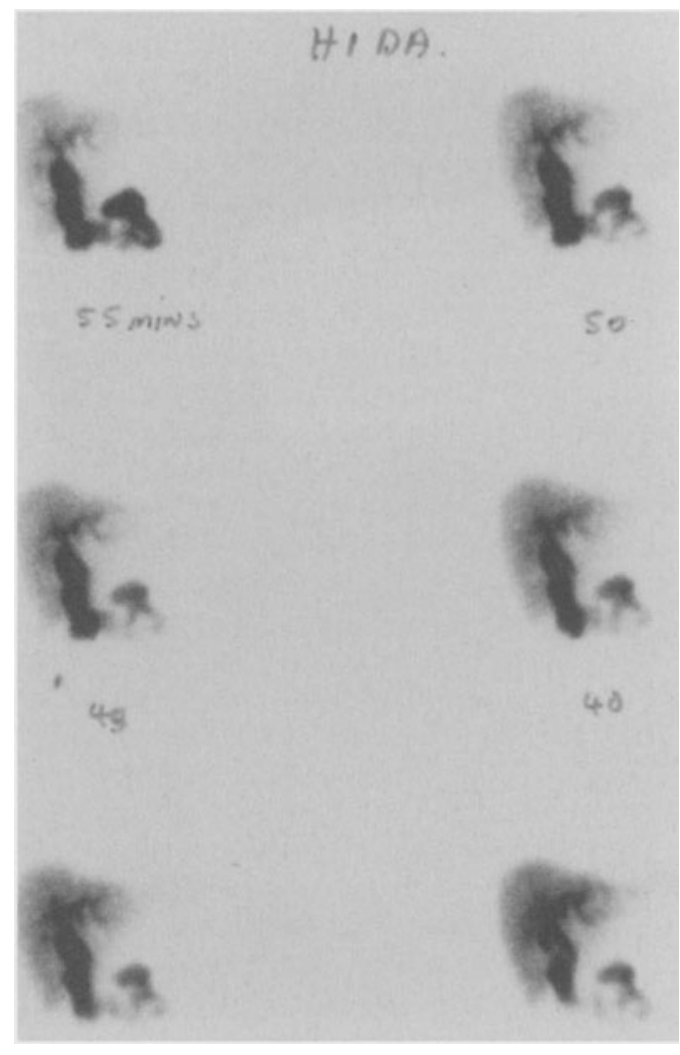

\section{Management of Specific Problems}

\section{Oral Disease}

Maintenance of oral hygiene is an important part of caring for patients who are HIV-positive. Gingivitis is common and of variable severity. Patients with gingivitis are best managed jointly with oral physicians and dentists. Therapy includes improved dental hygiene, antiseptic mouthwashes and the use of antibiotics such as metronidazole.

Oral candidiasis may respond to local therapy with antifungals such as amphotericin lozenges, or nystatin in the form of suspension or pastilles. Patients often relapse and need systemic therapy. Ketoconazole, fluconazole, and itraconazole can all be used (Table 5.4). Ketoconazole is cheaper than fluconazole but may be less effective (Laine et al. 1992b). Resistance to systemic antifungals is a common problem. Symptoms may initially be controlled by increasing the dose of antifungal therapy, but often parenteral amphotericin is the only useful form of therapy (Table 5.4).

Culture-proven HSV ulceration should be treated with acyclovir (Table 5.4). Five-day courses can be given, but most patients with AIDS require long-term suppressive therapy. 


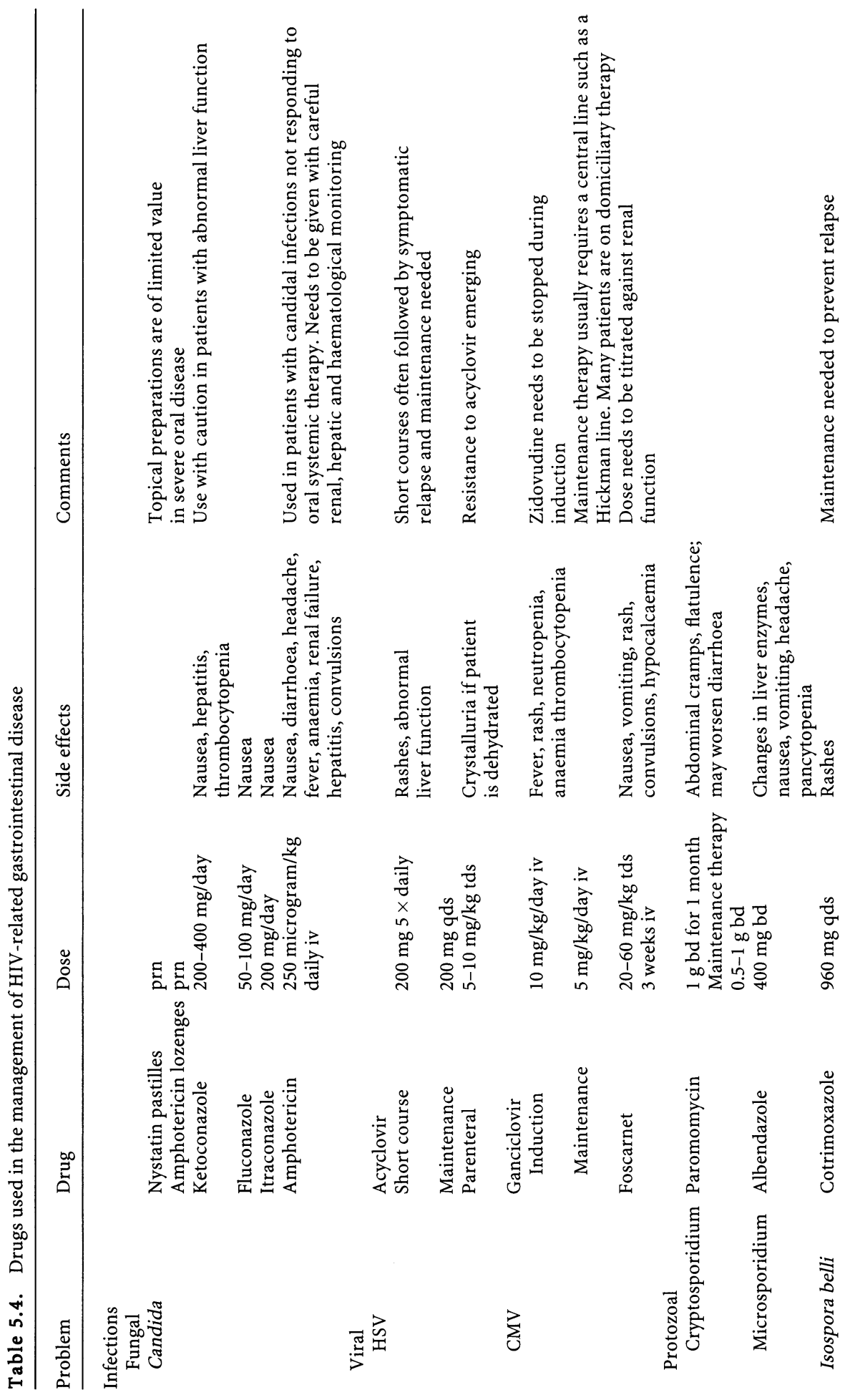




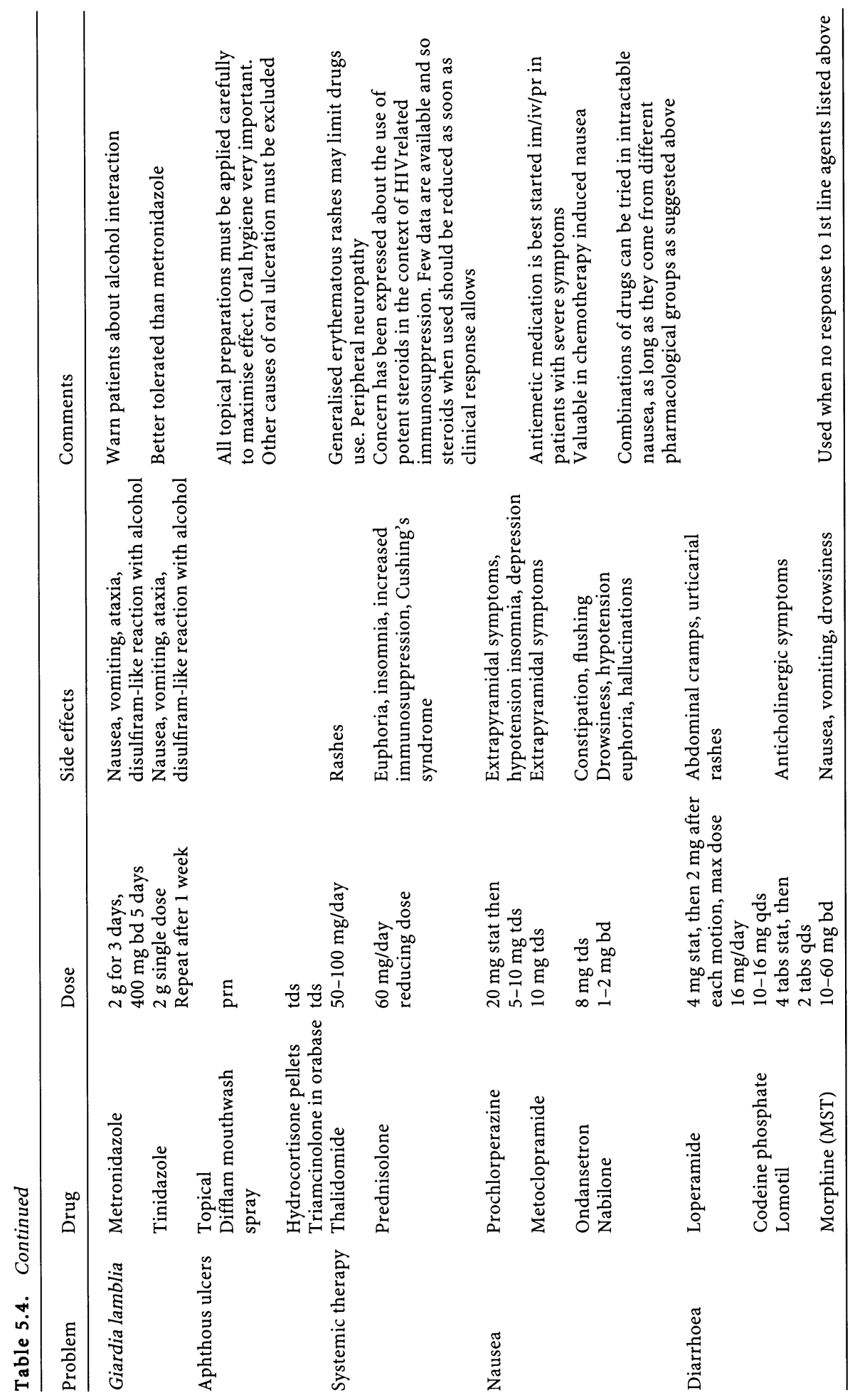


Mild cases of aphthous ulceration may be helped by gargles with chlorhexidine gluconate, or application of topical steroids such as triamcinolone in orabase. Oral thalidomide has been used to treat patients with giant aphthae, but one report has suggested that in HIV patients, thalidomide is associated with a high incidence of allergic rashes (Williams et al. 1991). High dose systemic steroids may achieve the same result more safely, but should be reduced as soon as possible.

Intraoral warts are best treated with cryotherapy but may be recurrent. In HIV associated xerostomia artificial saliva substitutes can be used, and citrus sweets provide a simple alternative.

\section{Oesophageal Disease}

Management of oesophageal candidiasis is with systemic antifungal drugs (Table 5.4). As discussed above, treatment is often empirical and in uncomplicated oesophageal candidiasis symptoms usually respond in under a week. Failure to respond to treatment is an indication for endoscopy to exclude a second pathology. In general, higher doses of antifungal therapy are required in oesophageal rather than oral candidiasis. Controversy exists as to the optimal duration of therapy, both for induction and maintenance. Induction therapy should be continued until there is resolution of oesophageal symptoms. The patients can then be kept under observation until symptoms recur, at which time long-term therapy should be started. Alternatively patients can be put on long-term therapy at first presentation. The advantage of the first policy is that patients will require less drug, which is both cheaper and may also reduce the incidence of drug toxicity.

CMV ulceration of the gastrointestinal tract is uncommon. Treatment of CMV oesophagitis is outlined in Table 5.4. Ganciclovir or foscarnet may be used (Dietrich et al. 1988; Nelson et al. 1991). Both must be given intravenously, and often necessitate the insertion of a central line, although many patients are able to administer their medication at home. There have been no comparative trials of foscarnet and ganciclovir in CMV oesophagitis; both drugs have been demonstrated to be effective in healing oesophageal disease, and the major difference between the two drugs is in their spectrum of toxicity (Table 5.4). Treatment is usually given as a 2-3-week induction course or until symptomatic and endoscopic resolution have occurred. $77 \%$ of patients responded completely to 3 weeks' treatment with foscarnet in one study, and the response to ganciclovir is similar (Blanshard 1992; Peters et al. 1991). A placebo-controlled trial of ganciclovir in AIDS patients with CMV colitis demonstrated improvement in 20/32 patients on the active drug. However a similar result was obtained in 11/30 patients on placebo (Dieterich et al. 1990). The role of maintenance therapy in CMV oesophagitis is also open to question. In one study, 13/17 patients who responded to an induction course of foscarnet for CMV oesophagitis without subsequent maintenance therapy did not experience relapse (Nelson et al. 1991). Zidovudine potentiates the myelotoxic effects of ganciclovir, and should not be prescribed during ganciclovir induction therapy. Healing of large ulcers may be complicated by stricture formation (Goodgame et al. 1991; Churchill et al. 1992).

Herpetic oesophagitis is treated with acyclovir (Table 5.4). Maintenance treatment is advised.

Often ulceration is seen in the oesophagus without a clear histological diagnosis. Repeat endoscopy is worthwhile, as CMV inclusions are sometimes seen in 
subsequent biopsies (Connolly et al. 1989b). Despite repeat endoscopy, some patients will fail to have a specific diagnosis, and aphthous ulcers may thus be diagnosed by exclusion. These are treated in a similar manner to oral aphthous ulcers. Dexamethasone combined with sucralfate has also been successfully used to treat oesophageal aphthous ulceration in patients with HIV (Sokol-Anderson et al. 1991).

\section{Abdominal Pain}

Management of abdominal pain depends on the results of clinical examination augmented by ancillary tests such as ultrasound and endoscopy. Epigastric pain may respond to an empirical course of an $\mathrm{H}_{2}$ antagonist, but symptoms which persist beyond 2 weeks of therapy require further investigation. Right upper quadrant pain together with raised alkaline phosphatase, or a dilated biliary tree suggests ASC.

\section{Gastrointestinal Bleeding}

The management of gut haemorrhage is no different to that of non-HIV patients. Bleeding KS is best managed conservatively. The role of chemotherapy or other modalities of therapy in advanced visceral KS remains unclear.

\section{Abnormal Liver Function and Jaundice}

Biochemical evidence of hepatitis in AIDS patients is very common. The aetiology may be multifactorial including acute or chronic carriage of hepatotropic viruses: hepatitis $A$ virus (HAV), hepatitis $B$ virus (HBV), hepatitis $C$ virus (HCV/Non-A, Non-B), and hepatitis D virus (HDV/delta). Opportunistic infections such as Mycobacterium avium intracellulare, infiltration with tumour, or hepatotoxic drugs (Table 5.5), may also present with abnormal liver function tests.

Hepatitis A, which is spread by oro-faecal transmission, occurs with increased frequency in homosexual men. Oro-anal contact (rimming) has been shown to be a risk factor. The infection may rarely be associated with prolonged cholestasis, but a chronic carrier state does not occur. HIV does not appear to alter the natural history of hepatitis $\mathrm{A}$. A vaccine is now available for the prevention of hepatitis A, but data about its use in patients with HIV are lacking.

HIV infection may alter the natural history of HBV in a number of ways. A cytotoxic T-cell response to HBV core proteins expressed on the surface of hepatocytes is thought to be important in the hepatic parenchymal inflammatory response to $\mathrm{HBV}$ replication, and in the eradication of infection. Pre-existing HIV infection with quantitative and/or qualitative CD4 cell defects may favour the establishment of chronic infection (Underhill et al. 1986). Following a course of HBV vaccine there is a lower anti-HBs response rate in the presence of HIV (Carne et al. 1987). HBV replication may be potentiated in the presence of HIV infection. The rate of spontaneous loss of HBe antigen with time may be reduced (Krogsgaard et al. 1987), and reactivation of viral replication may occur. HIV 
Table 5.5. Hepatotoxic drugs used in HIV disease

\begin{tabular}{l} 
Antifungals \\
Ketoconazole \\
Fluconazole \\
Amphotericin \\
Antituberculous \\
Isoniazid \\
Rifampicin \\
Antivirals \\
Acyclovir \\
Ganciclovir \\
Antibiotics \\
Cephalosporins \\
Cotrimoxazole \\
Ciprofloxacin \\
Pentamidine \\
Antiprotozoal \\
Pyrimethamine \\
\hline
\end{tabular}

infection in the chronic HBV carrier may decrease hepatic inflammatory activity as measured by the levels of transaminases and histology (MacDonald et al. 1987; Krogsgaard et al. 1987). Finally, HIV may diminish the response to therapy in chronic HBV infection.

Following the development of serological tests for HCV, it has become possible to study the epidemiology of this virus (Kuo et al. 1989). Initial tests lacked specificity, but the development of second generation ELISA and confirmatory RIBA tests has improved the diagnosis of HCV infection. It appears that although HCV is often associated with parenteral modes of transmission, usually following blood transfusion or in intravenous drug users, it is also sexually transmitted with an increased prevalence in homosexual men. A recent study from London looking at 1064 serum samples obtained from a sexually transmitted disease clinic, showed that $6.9 \%$ of homosexual men, compared with $1.0 \%$ of heterosexuals, had evidence of infection (Tedder et al. 1991). Carriage of antibodies to HCV was strongly associated with HIV and HBV seropositivity. It is possible that HIV can modify the natural history of HCV infection and further data is awaited.

$\mathrm{HDV}$ is an incomplete RNA virus that requires HB surface antigen for replication. HDV infection most commonly occurs in injecting drug users, or in patients subjected to repeated parenteral exposure such as haemophiliacs. The virus appears to be uncommon in homosexual men. Like HBV, HDV can present as a self-limiting viral infection, or may develop into a chronic carrier state. In this case there is a $70 \%$ chance of the patient developing cirrhosis. Currently there are no data on the possible interaction between HIV and HDV.

Investigation will be directed by the nature of the biochemical abnormalities, and the patient's other problems and treatment. It is important to exclude biliary obstruction with abdominal ultrasound. The role of percutaneous liver biopsy remains uncertain, with many conditions being diagnosed by other means including blood culture or bone marrow examination. A number of studies have 
shown the diagnostic rate of liver biopsy to vary between $24 \%$ and $80 \%$ (Cappell et al. 1990), and subsequent treatment may be of uncertain benefit. Liver biopsy may be more useful in certain subgroups of patients with HIV infection. A study from Harlem (New York) reviewed 48 biopsies from a group of patients, of whom $82 \%$ had a history of injecting drug use. Within this selected population, $33.3 \%$ of the biopsies had evidence of Mycobacterium tuberculosis infection and this information led to the initiation of anti-tuberculous chemotherapy (Comer et al. 1989).

\section{Pancreatobiliary Disease}

A syndrome which resembles primary sclerosing cholangitis is recognised as a cause of abnormal liver function in AIDS patients (Schneiderman et al. 1987; Viteri and Greene 1987; Dowsett et al. 1988; Cello et al. 1989). The typical presentation is with right upper quadrant pain, accompanied by a raised alkaline phosphatase. Approximately $50 \%$ of patients with AIDS sclerosing cholangitis (ASC) have fever, although only $15 \%$ are jaundiced. Ultrasound scans of the abdomen are abnormal in the majority, and show biliary tract dilatation. ${ }^{99 \mathrm{~m}} \mathrm{Tc}$-labelled iminodiacetic acid (IDA) scans of the hepatobiliary system typically demonstrate delayed excretion of tracer, or strictures, but endoscopic retrograde cholangiopancreatography (ERCP) is the definitive investigation. A number of different patterns of abnormality in the biliary tract are recognised. Papillary stenosis, and intrahepatic disease with beading and stricturing of the bile ducts, are each seen in around $15 \%$ of patients. A combination of these two abnormalities is seen in half the patients, whilst the remainder have extrahepatic strictures. The disease is commonly associated with cryptosporidiosis, microsporidiosis and CMV infection (Forbes et al. 1993; Pol et al. 1993). Endoscopic sphincterotomy may give pain relief in a proportion of patients with papillary stenosis. Liver function tests do not usually improve, and the prognosis is poor, with most patients dying within 6 months of diagnosis. The majority of patients can be managed conservatively with opiates (Forbes et al. 1993).

A syndrome of acalculous cholecystitis is also encountered in patients with HIV infection, either with or without co-existing sclerosing cholangitis (Kavin et al. 1986). The presentation is with right upper quadrant pain and tenderness, typically accompanied by fever and weight loss. Liver enzymes are often markedly elevated. Abdominal ultrasound may show thickening of the gallbladder wall and biliary dilatation. IDA scans and oral cholecystograms often show non-filling of the gallbladder. Cholecystectomy is effective in relieving symptoms in this condition. There is often evidence of CMV infection of the biliary tree, and CMV inclusions may be seen in the wall of the resected gallbladder.

Hyperamylasaemia and pancreatic duct abnormalities are frequently seen but are not usually associated with symptoms. Acute pancreatitis occurs in AIDS, most commonly as a result of treatment with dideoxyinosine (DDI) or intravenous pentamidine. CMV, Toxoplasma gondii, KS and lymphoma have all been implicated in acute pancreatitis in patients with AIDS (Brivet et al. 1987). Diabetes mellitus has been reported in two HIV-positive intravenous drug users without the usual immunological markers of type 1 diabetes, and a viral aetiology has been proposed (Vendrell et al. 1987). 


\section{Weight Loss/Anorexia}

Weight loss is a common symptom associated with HIV infection and individuals who lose more than $10 \%$ of their baseline weight within 6 months are said to have AIDS wasting syndrome (Centers for Disease Control 1987). In general, patients in developed countries tend to lose weight on an intermittant basis possibly as a result of active secondary infection (Grunfeld et al. 1992). In contrast AIDS patients from developing countries have progressive weight loss "slim disease" (Serwadda et al. 1985) resulting from untreated secondary infection. Weight loss is an important problem as prognosis is related to the degree of weight loss (Kotler et al. 1989).

The causes of weight loss are complex and several different factors may coexist in individual patients.

Anorexia may occur secondary to drug therapy, opportunistic infection, taste disturbance or oral discomfort resulting in inadequate food intake.

Malabsorption of fat, lactose, vitamin $\mathrm{B}_{12}$ and bile acids has been demonstrated (Miller et al. 1988; Kapembwa et al. 1989, 1990) and may occur throughout all stages of HIV infection. The mechanisms of malabsorption remain unclear but villous atrophy of varying severity has been described by many authors (Kotler et al. 1984; Cummins et al. 1990) (Fig. 5.7). This has been variably associated with crypt hyperplasia, or increase in crypt mitotic figures (Kotler et al. 1984; Cummins et al. 1990). Chronic inflammatory cells in the lamina propria are increased, together with intraepithelial lymphocytes (Greenson et al. 1991). When mucosal cellular infiltrates are examined immunocytochemically, it is found that the CD4/CD8 ratio is reversed in a similar manner to peripheral blood lymphocytes. This is caused by a selective depletion in CD4 helper lymphocytes, and an increase in CD8 cytotoxic lymphocytes; an increase in activated macrophages in the lamina propria is also seen (Jarry et al. 1990). Mucosal plasma cell production of immunoglobulin $\mathrm{A}$ has been shown to be reduced when examined using polyclonal rabbit anti-human immunoglobulin antibody (Kotler et al. 1987), and Ullrich (1989) has demonstrated the reduction or absence of $\beta$ glucosidase in the duodenal brush border in biopsies from HIV patients. Using electron microscopy a number of ultrastructural abnormalities have been identified, including damage to jejunal autonomic nerves in the lamina propria (Griffin et al. 1988). All of these changes may result from the presence of HIV in the mucosa, or HIV-infected lymphocytes migrating through the lamina propria and epithelium releasing cytokines which in turn affect epithelial cell kinetics.

Diarrhoea is discussed below and may result in profound weight loss especially in patients with cryptosporidiosis.

Active secondary infection may precipitate weight loss by inducing anorexia but metabolic disturbance has also been described. Basal energy expenditure is increased by up to $60 \%$ in AIDS patients with Mycobacterium avium-intracellulare infection (Kotler et al. 1989a). Treatment of active infection may lead to improved nutritional status (Kotler et al. 1989b). Increased $\alpha$-interferon production and disturbed lipid metabolism with hypertriglyceridaemia has been reported in AIDS patients (Grunfeld et al. 1992) but there is no direct relationship with wasting.

Management of weight loss necessitates a multidisciplinary approach involving clinicians and dieticians. Clinical examination and appropriate investigations 


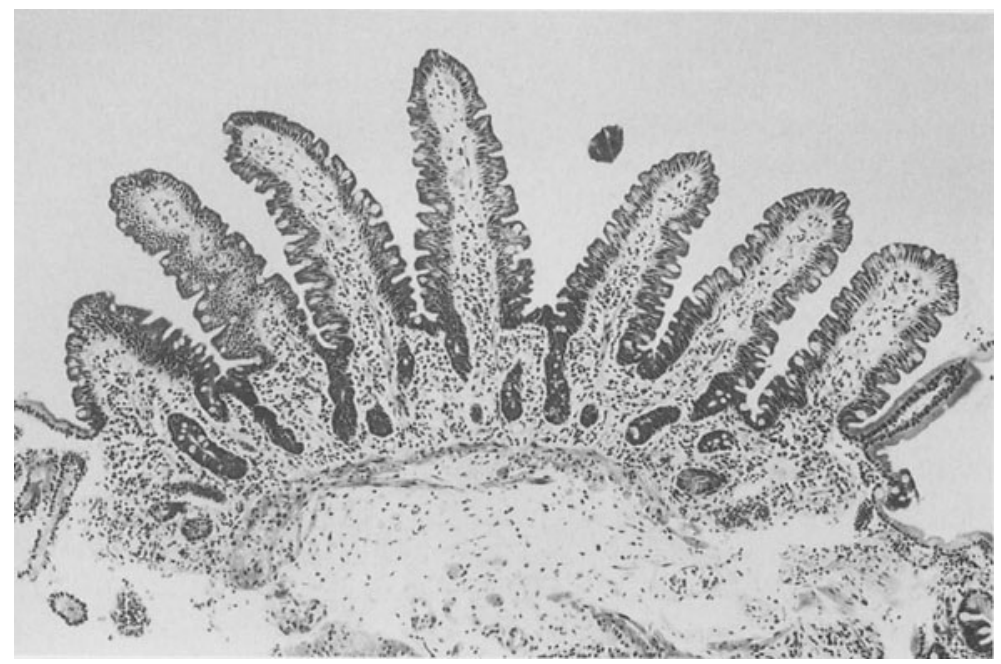

a

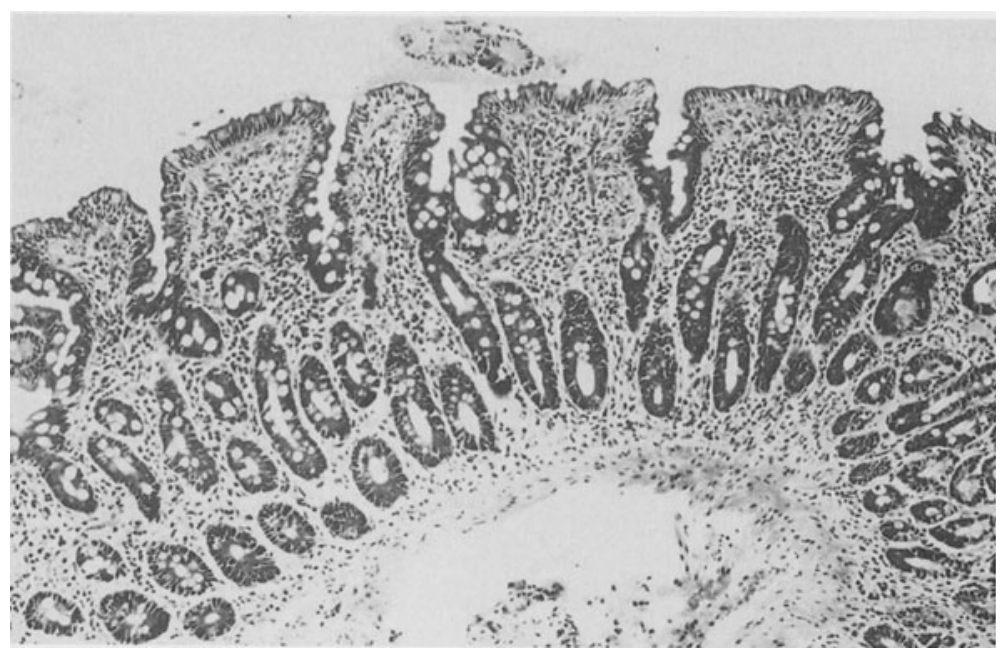

b

Fig. 5.7a,b. Small bowel biopsy from healthy control patient (a) and from an AIDS patient with diarrhoea and malabsorption showing increased chronic inflammatory cells in the lamina propria and crypt hyperplasia with villous atrophy (b).

will enable any secondary infection to be treated. In addition it may be possible to elucidate the likely factors leading to weight loss. A detailed dietary history will provide information necessary to plan a nutritional programme suitable for individual patients. Simple measures such as encouraging smaller, more frequent meals may be helpful. A wide variety of nutritional supplements are also available. Megestrol acetate (Megace) has been shown to be a useful appetite stimulant when given at a dose of $800 \mathrm{mg} /$ day (Van Roenn et al. 1988; Flynn et al. 1992). In patients unable to tolerate oral feeding enteral and parenteral feeding are alternative forms of nutrition but their efficacy and clinical indications are 
still evolving (Kotler et al. 1991; Singer et al. 1991). Enteral nutrition offers a safer and cheaper alternative to total parenteral nutrition (TPN). TPN is perhaps most useful in patients with severe diarrhoea, nausea and vomiting in whom fluid balance and control of symptoms has been difficult. In this case the perceived benefits may be due to fluid replacement rather than nutritional support. There is a need for controlled trials before further advice can be given.

\section{Diarrhoea}

Patients with symptoms lasting more than 2 weeks should be investigated. Some of the more common causes are discussed below.

\section{Bacterial Enteric Infections}

Bacterial enteric infections account for less than $5 \%$ of opportunistic infections in AIDS patients. One study from San Francisco showed a twentyfold increase in Salmonella infections (Celum et al. 1987). Non-typhoidal salmonellas such as $S$. typhimurium and $S$. enteritidis are particularly common. Shigella and Campylobacter infections are also more common. Patients present with severe diarrhoeal symptoms, and $45 \%$ of the patients in the San Francisco study had bacteraemia (Celum et al. 1987). It is important to exclude toxic megacolon with plain abdominal radiography (Fig. 5.8). Patients with toxic megacolon should be treated with aggressive medical therapy including intravenous fluid

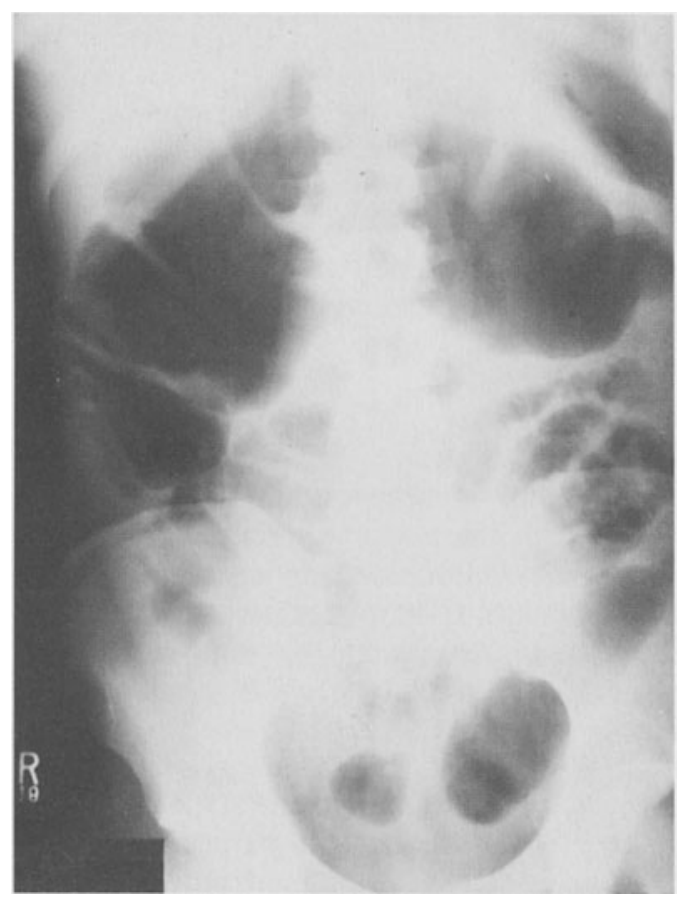

Fig. 5.8. Plain abdominal radiograph, showing toxic dilatation of proximal and transverse colon associated with CMV colitis. 
and antibiotics; surgery appears to carry a poor prognosis (Beaugerie et al. 1991). Organisms are usually sensitive to conventional therapy, but drugs may need to be given parenterally. Relapse of invasive salmonellosis following cessation of treatment is common and is an indication for secondary prophylaxis.

Post mortem studies of patients with Mycobacterium avium-intracellulare or other atypical mycobacterial infections show the gut is involved in $60 \%$ of cases. A characteristic endoscopic duodenal mucosal appearance has been described (Gray and Rabenek 1989). These organisms are commonly found in the environment and a single isolation from stool samples is probably not significant. In patients with diarrhoea and repeated positive samples, disseminated mycobacterial disease should be considered, especially if Mycobacteria are found at a second site, and if other findings such as fever and anaemia are present. Treatment regimens are still evolving, but the aim of treatment is symptomatic relief rather than cure of infection. A regimen of intravenous amikacin accompanied by oral ciprofloxacin, ethambutol and rifampicin has been effective in our unit (Scoular et al. 1991).

Intestinal spirochaetes occur in $36 \%$ of homosexual men (McMillan and Lee 1981), and have been traditionally regarded as non-pathogenic. However one case report suggested that in AIDS patients the organism, like so many other "non-pathogens", may cause symptoms (Nathwani et al. 1990). However, treatment of intestinal spirochaetosis makes little difference to diarrhoeal symptoms (Connolly et al. 1989c).

\section{Protozoa}

One of the manifestations of the "Gay Bowel" syndrome was the high prevalence of intestinal parasites. The pathogenicity of these organisms has been questioned, especially in the context of HIV infection. Entamoeba histolytica has been subspeciated on the basis of the electrophoretic mobility of its iso-enzymes into 22 zymodemes. The zymodemes found in homosexual men appear to be nonpathogenic even in HIV-positive individuals (Allason-Jones et al. 1988). Entamoeba coli, Entamoeba hartmanni, Endolinax nana and Iodamoeba buetschlii do not produce disease in humans. Blastocystis hominis is usually not associated with disease.

Cryptosporidium, a small $4.5 \mu \mathrm{m}$ organism, is one of the most common pathogens isolated from HIV-infected patients with diarrhoea. The parasite may be transmitted via a number of different routes. Initially the disease was thought to be a zoonosis, but water contamination, sexual and nosocomial transmission have all been reported (Current et al. 1983; D'Antonio et al. 1985; Soave et al. 1984; Ravn et al. 1991). Cryptosporidiosis occurs in both immunocompetent and immunosuppressed populations, although the disease is often more severe in the latter group. The degree of immunosuppression influences patient prognosis and HIV-infected patients with reasonable immune function may recover spontaneously from their cryptosporidial infection (Blanshard et al. 1992; McGowan et al. 1993). Clinically, patients present with watery diarrhoea which may vary in volume from 1 to $17 \mathrm{l}$ per day, together with abdominal pain and fever. Cryptosporidium has also been associated with sclerosing cholangitis (Dowsett 
et al. 1988). Diagnosis is discussed elsewhere. Treatment is supportive as no agent has shown convincing efficacy. Cryptosporidium is difficult to eradicate from the water supply as it is resistant to most agents used in conventional concentrations, and its small size allows it to pass through most filtration systems. The organism is heat-sensitive and immunosuppressed patients should be advised to boil water for drinking purposes.

Giardia lamblia is a common cause of diarrhoea. Patients present with watery diarrhoea, abdominal pain and flatulence. Trophozoites may be identified in faeces, but occasionally the organism is identified in duodenal aspirate, or on routine histopathology of duodenal biopsies. Treatment is with metronidazole or tinidazole, but relapse may occur.

Isospora belli is an opportunistic protozoan that produces diarrhoea in AIDS patients. Isosporiasis is uncommon in developed countries, but has been reported in $15 \%$ of AIDS patients in Haiti (Pape et al. 1989). The organism can be treated with trimethoprim-sulphamethoxazole, but relapse is common. Pyrimethamine may be used as secondary prophylaxis.

Microsporidia are perhaps the most recent organisms to be associated with HIVrelated diarrhoea (Muscat 1990; Eeftink Schattenkirk et al. 1991). There are over 700 species although only six have been associated with disease in immunocompromised humans. Hepatitis, peritonitis, keratopathy, conjunctivitis, nasal obstruction, and sclerosing cholangitis have all been reported in association with Microsporidia. Enterocytozoon bieneusi is the most common species associated with diarrhoea. Diagnosis is difficult as the spores are only $1.5 \mu \mathrm{m}$ in diameter and are best seen using electron microscopy. Stool samples and duodenal smears stained with Giemsa are being evaluated for use in identifying Microsporidia (Van Gool et al. 1990; Weber et al. 1992). Treatment is difficult. Chloroquine, tetracycline, and spiramycin have all shown some efficacy in suppressing Encephalitozoon cuniculi spore production in vitro (Waller 1979). Albendazole has shown promise in AIDS patients with microsporidiosis (Blanshard et al. 1991).

Coccidian parasites variously described as blue-green algae or cyanobacterium-like bodies have been described as an important cause of prolonged diarrhoea in travellers returning from the tropics (Pollok et al. 1992). These organisms may also affect patients with HIV infection and produce a prolonged illness characterised by watery diarrhoea and weight loss. Treatment with cotrimoxazole may be effective.

\section{Fungal Enteric Infections}

The isolation of yeasts from stool samples is a common laboratory finding of uncertain significance. Gupta and Ehrinpreis (1990) have described 10 cases of diarrhoea in a heterogeneous population of critically ill patients with non-HIV disease, which was characterised by the presence of Candida albicans in stool culture and a rapid therapeutic response to anti-fungal therapy. There are no similar reports in patients with AIDS. 


\section{Viral Enteric Infections}

By 50 years of age $50 \%$ of the population will have been exposed to the CMV and developed immunity. In homosexual men almost $90 \%$ have evidence of previous infection. As with other herpes viruses CMV remains latent within the host. The immunosuppression associated with HIV infection allows the virus to reactivate and cause symptoms. In AIDS patients CMV has been associated with choroidoretinitis, pneumonitis, encephalitis, oesophagitis, sclerosing cholangitis, hepatitis and adrenalitis. CMV colitis occurs in less than $5 \%$ of patients with AIDS (Jacobson et al. 1988). A recent case report demonstrated CMV proctitis associated with an HIV seroconversion illness (Gupta 1993). Symptoms of CMV colitis include bloody diarrhoea, abdominal pain and fever. Colonic perforation has also been reported (De Riso et al. 1989). Sigmoidoscopy may show diffuse erythema and mucosal ulceration. Occasionally the mucosal lesions which may be segmental are only found at colonoscopy. Diagnosis is histopathological and is made on the basis of characteristic CMV inclusion bodies, or detection of CMV antigen with monoclonal antibodies (Culpepper-Morgan et al. 1987). Treatment is with ganciclovir or foscarnet (Table 5.4). Response to induction therapy is relatively poor and early relapse common despite maintenance treatment (Dieterich et al. 1988; Peters et al. 1991; Blanshard 1992).

Adenovirus has been identified in $7.4 \%$ of HIV-infected homosexual men with diarrhoea, by using a combination of virus culture and transmission electron microscopy (Janoff et al. 1991). Only one of the patients had a potential copathogen to explain the diarrhoea. No specific treatment is available.

\section{KS and Lymphoma}

Visceral Kaposi's sarcoma and lymphoma can both involve the gastrointestinal tract and present with diarrhoea. In clinical practice this is not a major problem. In rare cases patients may abuse laxatives. Pseudomembranous colitis in HIVinfected patients is treated in the same way as in seronegative patients with oral vancomycin or metronidazole.

\section{Symptomatic Treatment}

The effective management of HIV-related diarrhoea depends on appropriate investigation to identify pathogens. Although in many cases this is possible, many organisms are of uncertain pathogenicity, and others respond poorly to specific treatment. Symptomatic treatment is therefore an important component of management in all cases. Fluid can be given orally in the form of glucose and electrolyte solutions. In patients with severe diarrhoea and vomiting, intravenous fluids may be needed. In all cases it is important to be aware of patients' home circumstances. The appropriate use of commodes and incontinence pads can do much to improve patients' quality of life.

It is possible to control the vast majority of diarrhoea by using anti-diarrhoeal agents in a step-wise manner as suggested below. There is no fixed regimen, and one can combine 1st line agents before moving on to more potent opiates. 


\section{Antidiarrhoeal Agents}

1st Line Therapy. Loperamide, diphenoxylate, codeine phosphate.

2nd Line therapy. Morphine (slow release preparation).

3rd Line Therapy. Intractable diarrhoea may respond to subcutaneous administration of diamorphine. Somatostatin and interleukin 2 have been used on an experimental basis without clear evidence of efficacy.

\section{Perianal Problems}

HSV is a difficult problem in the context of HIV-associated immunosuppression. Attacks tend to become more frequent, the symptoms are more severe, and the lesions more widespread. Response to short courses of acyclovir are often unsatisfactory, and most patients require maintenance therapy (Table 5.4). In spite of adequate suppressive therapy, some individuals develop resistant ulceration which fails to respond to intravenous acyclovir (Erlich et al. 1989). This has been found to be partially due to the emergence of thymidine kinase-deficient strains of HSV. Foscarnet is not phosphorylated by viral thymidine kinase, and may be helpful in this situation.

HPV infection is common in homosexual men. Perianal warts tend to be more resistant to therapy in immunosuppressed patients with HIV, but more worrying is the association between HPV infection, anal intra-epithelial neoplasia (AIN), and HIV. It has been suggested that the incidence of anorectal cancer in homosexual men is $25-50$ times that of heterosexual controls (Daling et al. 1982). In a more recent study anorectal dysplasia in homosexual men was associated with a history of anal warts, frequent receptive anal intercourse, antibody to HIV and a low CD4/CD8 lymphocyte ratio (Frazer et al. 1986). Perianal warts can be treated with local application of podophyllin, or cryotherapy. Resistant lesions may be removed surgically, but recurrence is common. Anal intra-epithelial neoplasia may be diagnosed on biopsy, but it is uncertain what percentage will develop local carcinoma. Careful proctoscopic examination and follow-up is important, but no specific treatment is recommended.

\section{Kaposi’s Sarcoma/Lymphoma}

Treatment of gastrointestinal KS is indicated if there are major symptoms (Spittle 1989). Local lesions in the mouth may respond to radiotherapy, but chemotherapy is the main modality of treatment. A variety of chemotherapy regimes have been used. Complex combination chemotherapy has the disadvantage of causing increased immunosuppression and increased risk of opportunistic infections. Simple regimes using vincristine and bleomycin alone or in combination produce a response in up to $75 \%$ of patients with a low risk of bone marrow suppression (Gill et al. 1990). Alpha interferon may be used to induce remission of KS in patients with CD4 counts of 200 or more, but high doses are needed, and side effects such as fatigue, fever and alopecia are common. This form of treatment is not beneficial in more immunosuppressed patients. The outlook with 
lymphoma is generally poor, but depends on the histological characteristics of the tumour, with large non-cleaved cell tumours having the best prognosis. Treatment with modified combination chemotherapy regimes may produce a clinical response, at the expense of increased immunosuppression.

\section{Future Developments}

With the advent of laboratory techniques such as immunohistochemistry, in-situ hybridisation and polymerase chain reaction, it has become possible to study HIV enteropathy in much more detail. Villous atrophy has been described using standard histopathological methods, and immunohistochemical staining has identified a number of features such as selective depletion of T4 lymphocytes within the lamina propria. Current research may clarify how HIV interacts with the various cellular components of the gut mucosa, and whether local release of cytokines mediates enterocyte damage.

Improved health care and the use of antiretroviral therapy has meant that patients with AIDS are surviving for longer periods of time. One consequence of this has been the emergence of drug resistance. Oro-pharyngeal candidiasis, perianal herpes simplex infection and CMV ulceration have shown resistance to treatment with conventional agents.

Gastrointestinal CMV disease is a late manifestation of AIDS and has a poor prognosis. Consequently it has been difficult to assess the impact of anti-CMV therapy. Ganciclovir has been used (Dieterich et al. 1988), and now there is evidence that foscarnet may be efficacious (Hawkins et al. 1991). A novel form of therapy with TI-23 (a human monoclonal anti-CMV antibody) may offer hope for the future (Petersen et al. 1991).

KS is known to occur in homosexual men without any evidence of HIV infection (Safai et al. 1991). This and other epidemiological evidence suggests that an enteric sexually transmitted agent, possibly viral, may be responsible (Beral et al. 1992; Soriano et al. 1991). Treatment of visceral KS remains difficult. Combination chemotherapy and interferon have both been tried, but studies tend to be small with poorly defined end points. $\mathrm{DAB}_{486} \mathrm{IL}-2$ is a recombinant fusion protein composed of human IL-2 and cytotoxic fragments of diphtheria toxin. It is thought to act by binding to IL-2 receptors on KS cells. A preliminary study in 2 patients with chemotherapy-resistant KS demonstrated a $30 \%$ reduction in cutaneous lesions (LeMaistre et al. 1991).

Following the development of serological tests for HCV antibodies, several centres are carrying out sero-epidemiological studies. Chirianni investigated 206 Italian HIV seropositive patients. $47 \%$ of intravenous drug users (74/155), $62 \%$ of post transfusion patients $(5 / 8), 20 \%$ of homosexual men $(4 / 20)$ and $8.7 \%$ of heterosexuals (2/23) were HCV seropositive (Chirianni et al. 1991). In the near future we are likely to see a rapid growth in information about the natural history of HCV and its interactions with HIV and HBV.

\section{References}

Allason-Jones E, Mindel A, Sargeaunt P et al. (1988) Outcome of untreated infection with Entamoeba histolytica in homosexual men with and without HIV antibody. Br Med J 297: 654-657 
Bartelsman JF, Sars PR, Tygat GN (1989) Gastrointestinal complications in patients with acquired immunodeficiency. Scand J Gastroenterol 24: 112-117

Beaugerie L, Goujard F, Gharakhanian et al. (1991) Etiology and Management of Toxic Megacolon in AIDS Patients. VII International Conference on AIDS, Florence (abstract M.B. 2204)

Beral V, Peterman TA, Berkelman RL, Jaffe HN (1990) Kaposi's sarcoma among persons with AIDS: a sexually transmitted infection? Lancet 335: 123-128

Beral V, Bull D, Jaffe $\mathrm{H}$ et al. (1991) Is the risk of Kaposi's sarcoma in AIDS patients in Britain increased if sexual partners came from the United States or Africa. Br Med J 302: 624-625

Beral V, Bull D, Darby S, et al. (1992) Risk of Kaposi's sarcoma and sexual practices associated with faecal contact in homosexual or bisexual men with AIDS. Lancet 339: 632-635

Blanshard C (1992) Treatment of HIV-related cytomegalovirus disease of the gastrointestinal tract with foscarnet. J Acq Imm Defic Syn 5 (Suppl 1): S25-S28

Blanshard C, Peacock C, Ellis D, Gazzard B (1991) Treatment of intestinal microsporidiosis with Albendazole. VII International Conference on AIDS, Florence (abstract W.B. 2265)

Blanshard C, Jackson AM, Shanson DC, Francis N, Gazzard BG (1992) Cryptosporidiosis in HIVseropositive patients. Q J Med 85: 813-823

Bourinbaiar AS, Phillips DM (1991) Transmission of human immunodeficiency virus from monocytes to epithelia. J Acq Imm Defic Syn 4: 56-63

British Society of Gastroenterology (1989) Cleaning and disinfection of equipment for gastrointestinal flexible endoscopy: recommendations of a working party of the British Society of Gastroenterology. Gut 29: 1134-1151

Brivet F, Coffin B, Bedossa P et al. (1987) Pancreatic lesions in AIDS. Lancet ii: 570

Cappell MS, Schwartz MS, Biempica L (1990) Clinical utility of liver biopsy in patients with serum antibodies to the human immunodeficiency virus. Am J Med 88: 123-130

Carne CA, Weller IVD, Waite J et al. (1987) Impaired responsiveness of homosexual men with HIV antibodies to plasma derived hepatitis B vaccine. Br Med J 294: 866-868

Cello JP (1989) Acquired immunodeficiency syndrome cholangiopathy: spectrum of disease. Am J Med 86: 539-546

Celum CL, Chaisson RE, Rutherford GW, Barnhart JL, Echenberg DF (1987) Incidence of salmonellosis in patients with AIDS. J Infect Dis 156; 6:998-1001

Centers for Disease Control (1987) Revision of the CDC surveillance case definition for acquired immunodeficiency syndrome. MMWR 36 (Suppl 2S): 3S-15S

Chirianni A, Abrescia N, Tullio Cataldo et al. (1991) Anti-HCV prevalence in HIV infected patients. VII International Conference on AIDS, Florence (abstract W.B. 87)

Churchill DR, Kenton-Smith J, Malin A (1992) Oesophageal stricture complicating cytomegalovirus ulceration in a patient with AIDS. J Infect 25: 108-109

Clotet B, Grifol M, Parro O et al. (1986). Asymptomatic esophageal candidiasis in the acquiredimmunodeficiency-syndrome-related-complex. Ann Intern Med 105: 145

Comer GM, Mukherjee S, Scholes JV, Holness LG, Clain DJ (1989) Liver biopsies in the acquired immunodeficiency syndrome: influence of endemic disease and drug abuse. Am J Gastroenterol 84; 12: 1525-1531

Connolly GM, Forbes A, Gleeson JA (1989a) Short communication: investigation of upper gastrointestinal symptoms in patients with AIDS. AIDS 3: 453-456

Connolly GM, Hawkins D, Harcourt-Webster JN, et al. (1989b) Oesophageal symptoms, their causes, treatment, and prognosis in patients with the acquired immunodeficiency syndrome. Gut 30: 1033-1039

Connolly GM, Shanson D, Hawkins DA, Harcourt-Webster JN, Gazzard BG (1989c) Noncryptosporidial diarrhoea in human immunodeficiency virus (HIV) infected patients. Gut 30: $195-200$

Culpepper-Morgan JA, Kotler DP, Scholes DP, Tierney AR (1987) Evaluation of diagnostic criteria for mucosal cytomegalic inclusion disease in the acquired immunodeficiency syndrome. Am J Gastroenterol 82; 12: 1264-1270

Cummins AG, La Brooy JT, Stanley DP, Rowland R, Shearman DJC (1990) Quantitative histological study of enteropathy associated with HIV infection. Gut $31: 317-321$

Current WL, Reese NC, Ernst JV et al. (1983) Human cryptosporidiosis in immunocompetent and immunodeficient persons. N Engl J Med 308: 289-296

Daling JR, Weiss NS, Klopfenstein LL et al. (1982) Correlates of homosexual behaviour and the incidence of anal cancer. JAMA 247: 1988-1990

D'Antonio RG, Winn RE, Taylor JP et al. (1988) A waterborne outbreak of cryptosporidiosis in normal hosts. Ann Int Med 103: 886-888

De Riso AJ, Kemeny MM, Torres RA, Oliver JM (1989) Multiple jejunal perforations secondary to cytomegalovirus in a patient with acquired immunodeficiency syndrome. Dig Dis Sci 34: 623-629 
Dieterich DT, Chachoua, LaFleur F, Worrell C (1988) Ganciclovir treatment of gastrointestinal infections caused by cytomegalovirus in patients with AIDS. Rev Inf Dis 10 (Suppl 3): 532-537

Dieterich D, Kotler D, Busch D et al. (1990) Randomized, placebo-controlled study of ganciclovir treatment of cytomegalovirus (CMV) colitis in AIDS patients (PTS). VI International Conference on AIDS, San Francisco (abstract F.B.94)

Dowsett JF, Miller R, Davidson R et al. (1988) Sclerosing cholangitis in acquired immunodeficiency syndrome. Scand J Gastroenterol 23: 1267-1274

Eeftink Schattenkirk JKM, van Gool T, van Ketel RJ et al. (1991) Clinical significance of small intestinal microsporidiosis in HIV-1-infected individuals. Lancet 337: 895-898

Erlich KS, Mills J, Chatis P et al. (1989) Acyclovir resistant herpes simplex virus infections in patients with the acquired immunodeficiency syndrome. N Engl J Med 320: 293-296

Fauci AS, Macher AM, Longo DC et al. (1984) Acquired immunodeficiency syndrome: epidemiologic, clinical, immunologic and theraputic considerations. Ann Intern Med 100: 92-106

Flynn N, Enders S, Oster M, Cone L, Hooten T (1992) Megestrol acetate $800 \mathrm{mg} /$ day vs placebo for treatment of weight loss and anorexia in AIDS patients. VIIIth International Conference on AIDS, Amsterdam, (abstract PoB 3687)

Forbes A, Blanshard C, Gazzard B (1993) Natural history of AIDS related sclerosing cholangitis: a study of 20 cases. Gut 34: 116-121

Francis ND, Boylston AW, Roberts AHG, Parkin JM, Pinching AJ (1989) Cytomegalovirus infection in gastrointestinal tracts of patients infected with HIV-1 or AIDS. J Clin Pathol 42: 1055-1064

Frazer IH, Crapper RM, Medley G et al. (1986) Association between anorectal dysplasia, human papilloma virus and human immunodeficiency virus in homosexual men. Lancet i: 657-660

Friedman SL, Wright TL, Altman DF (1985) Gastrointestinal Kaposi's sarcoma in patients with acquired immunodeficiency syndrome. Endoscopic and autopsy findings. Gastroenterology 89: $102-108$

Gill P, Rarick M, Bernstein-Singer M et al. (1990) Treatment of advanced Kaposi's sarcoma using a combination of bleomycin and vincristine. Am J Clin Oncol 13: 315-319

Goodgame RW, Ross PG, Kim HS, Hook AG, Sutton FM (1991) Esophageal stricture after cytomegalovirus ulcer treated with ganciclovir. J Clin Gastroenterol 13: 678-681

Gray JR and Rabenek L (1989) Atypical mycobacterial infection of the gastrointestinal tract in AIDS patients. Am J Gastroenterol 84: 1521-1524

Greenson JK, Belitsos PC, Yardley JH, Bartlett JG (1991) AIDS enteropathy: occult enteric infections and duodenal mucosal alterations in chronic diarrhoea. Ann Intern Med 114: 366-372

Greenspan JS, Greenspan D, Lennette ET et al. (1985) Replication of Epstein-Barr virus within the epithelial cells of oral "hairy" leukoplakia, an AIDS-associated lesion. N Engl J Med 313: 1564-1571

Griffin GE, Miller A, Batman P et al. (1988) Damage to jejunal intrinsic autonomic nerves in HIV infection. AIDS 2: 379-382

Grunfeld C, Pang M, Shimizu L, Shigenaga JK, Jensen P, Feingold KR (1992) Resting energy expenditure, caloric intake, and short term weight change in human immunodeficiency virus infection and the acquired immunodeficiency syndrome. Am J Clin Nutr 55: 455-460

Grunfeld C, Pang M, Doerrier W, Shigenaga JK, Jensen P, Feingold KR (1992) Lipids, lipoproteins, triglyceride clearance and cytokines in human immunodeficiency virus infection and the acquired immunodeficiency syndrome. J Clin Endocrinol Metab 74: 1045-1052

Gupta KK (1993) Acute immunosuppression with seroconversion. N Engl J Med 328: 288-289

Gupta TP and Ehrinpreis MN (1990) Candida associated diarrhoea in hospitalised patients. Gastroenterology 98: 780-785

Hawkins D, Nelson M, Connolly G, Francis N, Gazzard B (1991) Foscarnet in the treatment of cytomegalovirus infection of the oesophagus and colon. VII International Conference on AIDS, Florence (abstract W.B. 2262)

Hillman RJ, Gopal Rao G, Harris JRW, Taylor-Robinson D (1990) Ciprofloxacin as a cause of Clostridium difficile-associated diarrhoea in an HIV antibody positive patient. J Infect 21: 205-207

Jacobson MA, O'Donnell JJ, Porteous D, Brodie HR, Feigal D, Mills J (1988) Retinal and gastrointestinal disease due to cytomegalovirus in patients with the acquired immune deficiency syndrome: prevalence, natural history and response to ganciclovir therapy. Q J Med 67: 473-486

Janoff EN, Orenstein JM, Manischewitz JF, Smith PD (1991) Adenovirus colitis in the acquired immunodeficiency syndrome. Gastroenterology 100: 976-979

Jarry A, Cortez A, Renee A, Muzeau F, Brousse N (1990) Infected cells and immune cells in the gastrointestinal tract of AIDS patients. An immunohistochemical study of 127 cases. Histopathology 16: $133-140$

Kapembwa MS, Batman PA, Fleming SC et al (1989) HIV enteropathy. Lancet ii: 1521-1522 
Kapembwa MS, Bridges C, Joseph AE, Fleming SC, Batman P, Griffin GE (1990) Ileal and jejunal absorptive function in patients with AIDS and enterococcidial infection. J Infect 21: 43-53

Kavin H, Jonas RB, Chowdhury L, Kabin S (1986) Acalculous cholecystitis and cytomegalovirus infections in the acquired immunodeficiency syndrome. Ann Intern Med 104: 53-54

Kazlow PG, Shah K, Benkov KJ, Dische R, Leleiko NS (1986) Oesophageal cryptosporidiosis in a child with the acquired immunodeficiency syndrome. Gastroenterology 91: 1301-1303

Kelly GE, Stanley BS, Weller IVD (1990) The natural history of human immunodeficiency virus infection: a five year study in a London cohort of homosexual men. Genitourin Medicine 66: 238-243

Kitchen VS, Helbert M Francis ND et al (1990) Epstein-Barr virus associated oesophageal ulcers in AIDS. Gut 31: 1223-1225

Klein RS, Harris CA, Small CB et al (1984) Oral candidiasis in high risk patients as the initial manifestation of the acquired immunodeficiency syndrome. N Engl J Med 311: 354-358

Knowles DM, Chomilak GA, Subar M et al. (1988) Lymphoid neoplasia associated with the acquired immune deficiency syndrome (AIDS). Ann Intern Med 108: 744-753

Kotler DP (1989) Intestinal and hepatic manifestations of AIDS. Adv Intern Med 34: 43-71

Kotler DP, Gaetz JP, Lange M, Klein EB, Holt PR (1984) Enteropathy associated with the acquired immunodeficiency syndrome. Ann Intern Med 101: 421-428

Kotler DP, Scholes JV, Tierney AR (1987) Intestinal plasma cell alterations in acquired immunodeficiency syndrome. Dig Dis Sci 32: 129-138

Kotler DP, Tierney AR, Wang J, Pierson RN (1989a) Magnitude of body-cell-mass depletion and the timing of death from wasting in AIDS. Am J Clin Nutr 50: 444-447

Kotler DP, Tierney AR, Altilio D et al. (1989b) Body mass repletion during ganciclovir treatment of cytomegalovirus infections in patients with acquired immunodeficiency syndrome. Arch Intern Med 149: 901-905

Kotler DP, Tierney AR, Ferraro R, Cuff P, Wang J, Pierson RN (1991) Enteral alimentation and repletion of body cell mass in malnourished patients with acquired immunodeficiency syndrome. Am J Clin Nutr 53: 149-154

Krogsgaard K, Lindhart BO, Nielsen JO et al (1987) The influence of HTLV-III infection on the natural history of hepatitis $\mathrm{B}$ virus infection in male homosexual HBsAg carriers. Hepatology 1: 37-41

Kuo G, Choo QL, Alter HJ (1989) An assay for circulating antibodies to a major etiologic virus of human non-A, non-B hepatitis. Science 244: 362-364

Laine L, Bonacini M, Sattler F, Young T, Sherrod A (1992a) Cytomegalovirus and Candida esophagitis in patients with AIDS. J Acq Imm Defic Syn 5: 605-609

Laine L, Dretler R, Conteas C et al. (1992b) Fluconazole compared with ketoconazole for the treatment of Candida esophagitis in AIDS. Ann Intern Med 117: 655-660

LeMaistre CF, Craig F, Smith J et al. (1991) Phase I/II evaluation of an IL-2 receptor targeted fusion toxin, $\mathrm{DAB}_{486} \mathrm{IL}-2$, for treatment of AIDS-associated Kaposi's sarcoma. VII International Conference on AIDS, Florence (abstract TU.B.85)

Levy JA, Margaretten W, Nelson J (1989) Detection of HIV in enterochromaffin cells in the rectal mucosa of an AIDS patient. Am J Gastroenterol 84; 7: 787-789

Ma P, Soave R (1983) Three-step stool examination for cryptosporidiosis in 10 homosexual men with protracted watery diarrhoea. J Infect Dis 147: 824-828

McDonald JA, Harris S, Waters JA, Thomas HC (1987) Effect of human immunodeficiency virus (HIV) infection on chronic hepatitis B viral antigen display. J Hepatol 4: 337-342

McGowan I, Hawkins AS, Weller IVD (1993) The natural history of cryptosporidial diarrhoea in HIVinfected patients. AIDS 7: 349-354

McMillan A, Lee FD (1981) Sigmoidoscopic and microscopic appearance of the rectal mucosa in homosexual men. Gut 22: 1035-1041

Miller ARO, Griffin GE, Batman P et al. (1988) Jejunal mucosal architecture and fat absorption in male homosexuals infected with human immunodeficiency virus. Q J Med 69: 1009-1119

Miller RF (1990) Nuclear medicine and AIDS. Eur J Nucl Med 16: 103-118

Muscat I (1990) Editorial: Human microsporidiosis. J Infect Dis 21: 125-129

Nathwani D, McWhinney PHM, Green ST, Boyd JD (1990) Intestinal spirochaetosis in a man with the acquired immune deficiency syndrome (AIDS). J Infect 21;3:318-319

Nelson J, Reynolds-Kohler C, Margaretten W, Wiley CA, Reese CE, Levy JA (1988) Human immunodeficiency virus detected in bowel epithelium from patients with gastrointestinal symptoms. Lancet i: $259-262$ 
Nelson MR, Connolly GM, Hawkins DA, Gazzard BG (1991) Foscarnet in the treatment of cytomegalovirus infection of the esophagus and colon in patients with the acquired immunodeficiency syndrome. Am J Gastroenterol 86: 876-881

Nelson M, Shanson D, Hawkins D, Gazzard B (1992) Salmonella, Campylobacter and Shigella in HIVseropositive patients. AIDS 6: 1495-1498

Pape JW, Verdier R, Johnson WD (1989) Treatment and prophylaxis of Isospora belli infection in patients with the acquired immunodeficiency syndrome. N Eng J Med 320: 1044-1047

Parente F, Cernushi M, Rizzardini G, Lazzarin A, Valsecchi L, Bianchi-Porro G (1991) Opportunistic infections of the oesophagus not responding to oral systemic antifungals in patients with AIDS: their frequency and treatment. Am J Gastroenterol 86: 1729-1734

Perrone V, Pergola M, Abate G et al. (1981) Protein-losing enteropathy in a patient with generalised Kaposi's sarcoma. Cancer 47: 588-591

Peters BS, Beck EJ, Anderson et al. (1991) Cytomegalovirus infection in AIDS. Patterns of disease, response to therapy and trends in survival. J Infect 23: 129-137

Petersen E, Gray J, Grayson J et al. (1991) Therapy with human monoclonal antibody (Mab) to cytomegalovirus (TI-23). VII International Conference on AIDS, Florence (abstract W.B. 2291)

Pluda JM, Yarchoan R, Jaffee ES et al. (1990) Development of non-Hodgkin lymphoma in a cohort of patients with severe HIV infection on long term anti-retroviral therapy. Ann Intern Med 113: 276-282

Pol S, Romana CA, Richard S et al. (1993) Microsporidia infection in patients with the human immunodeficiency virus and unexplained cholangitis. N Engl J Med 328: 95-99

Pollok RCG, Bendall RP, Moody A, Chiodini PL, Churchill DR (1992) Traveller's diarrhoea associated with cyanobacterium-like bodies. Lancet 340: 556-557

Quinnan GV, Masur H, Rook AH et al. (1984) Herpes virus infections in the acquired immune deficiency syndrome. JAMA 252: 72-77

Rabeneck L, Popovic M, Gartner S et al. (1990) Acute HIV infection presenting with painful swallowing and esophageal ulcers. JAMA 263; 7: 2318-2322

Ravn P, Lundgren JD, Kjaeldgaard P et al. (1991) Nosocomial outbreak of cryptosporidiosis in AIDS patients. Br Med J 302: 277-280

Resnick L, Herbst JS, Ablastin DV et al. (1988) Regression of oral hairy leukoplakia after orally administered acyclovir therapy. JAMA 259: 384-388

Safai B, Peralta H, Menzies K et al. (1991) Kaposi's sarcoma amongst HIV-seronegative high risk population. VII International Conference on AIDS, Florence (abstract TU.B. 83)

Schneiderman DJ, Cello JP, Laing FC (1987) Papillary stenosis and sclerosing cholangitis in the acquired immunodeficiency syndrome. Ann Intern Med 106: 546-549

Scoular A, French P, Miller RF (1991) Mycobacterium avium-intracellulare infection in the acquired immunodeficiency syndrome. Br J Hosp Med 46: 295-300

Serwadda D, Mugerwa RD, Sewankambo KN et al. (1985) Slim disease: a new disease in Uganda and its association with HTLV-III infection. Lancet 2: 849-852

Sheather AL (1953) The detection of intestinal protozoa and mange parasites by a flotation technique. J Comp Pathol 36: 268-275

Singer P, Rothkopf MM, Kvetan V, Kirvela O, Gaare J, Askanazi J (1991) Risks and benefits of home parenteral nutrition in the acquired immunodeficiency syndrome. J Parenter Enteral Nutr 15: 75-79

Soave R, Danner RL, Honig CL et al. (1984) Cryptosporidiosis in homosexual men. Ann Intern Med 100: 504-511

Sokol-Anderson ML, Prelutsky DJ, Westblom TU. (1991) Giant esophageal aphthous ulcers in AIDS patients: treatment with low-dose corticosteroids. AIDS 5: 1537-1538

Soriano V, Hewlett I, Friedman-Kien AE, Tor J, Huang X, Epstein L (1991) Definitive exclusion of HIV infection in a Kaposi's sarcoma bisexual man. Suggestions on a pathogenic model of KS. VII International Conference on AIDS, Florence (abstract TU.B. 82)

Spittle MF (1989) Diagnosis and treatment of Kaposi's sarcoma. J Antimicrob Chemother 23 Suppl A: 127-135

Tavitian A, Raufman JP, Rosenthal LE (1986) Oral candidiasis as a marker for oesophageal candidiasis in the acquired immunodeficiency syndrome. Ann Intern Med 104: 54-55

Tedder RS, Gilson RJC, Briggs $\mathrm{M}$ et al. (1991) Hepatitis C virus: evidence for sexual transmission. $\mathrm{Br}$ Med J 302: 1299-1302

Theise ND, Rotterdam H, Dieterich D (1991) Cytomegalovirus esophagitis in AIDS: diagnosis by endoscopic biopsy. Am J Gastroenterol 86: 1123-1126

Ullrich R, Zeitz M, Heise W, L'age M, Hoffken G, Riecken EO (1989) Small intestinal structure and function in patients infected with human immunodeficiency virus (HIV): Evidence for HIV induced enteropathy. Ann Intern Med 111: 15-21 
Underhill GS, Jeffries DJ, Forster GE, Harris JR (1986) Correlation between fulminant form of viral hepatitis and retrovirus infection associated with AIDS. Br Med J 292: 1080-1081

Van Gool T, Hollister WS, Eeftinck Schattenkerk J et al. (1990) Diagnosis of Enterocytozoon bienusi microsporidiosis in AIDS patients by recovery of spores from faeces. Lancet 336: 697-698

Van Roenn JH, Murphy RL, Weber KM, Williams LM, Weitzman SA (1988) Megestrol acetate for treatment of cachexia associated with human immunodeficiency virus (HIV) infection. Ann Intern Med 109: 840-841

Vendrell J, Nubiola A, Goday A et al. (1987) HIV and the pancreas. Lancet ii: 1212

Viteri AL and Greene JF (1987) Bile duct abnormalities in the acquired immune deficiency syndrome. Gastroenterology 92: 2014-2018

Waller T (1979) Sensitivity of Encephalitozoon cuniculi to various temperatures, disinfectants and drugs. Lab Anim 13: 227-230

Watkins EB, Findlay P, Gelmann E, Lane HC, Zabell A (1989) Enhanced mucosal reactions in AIDS patients receiving oropharyngeal irradiation. Int J Radiation Oncol. Biol. Phys 13: 1403-1408

Weber JN, Thom S, Barrison I et al. (1987) Cytomegalovirus colitis and oesophageal ulceration in the context of AIDS: clinical manifestations and preliminary report of treatment with Foscarnet (phosphonoformate). Gut 28: 482-487

Weber R, Bryan RT, Owen RL, Wilcox CM, Gorelkin L, Visvesvara GS (1992) Improved lightmicroscopical detection of microsporidia spores in stool and duodenal aspirates. N Engl J Med 326: 161-166

Wilcox CM, Diehl, Cello JP, Margaretten W, Jacobson MA (1990) Cytomegalovirus esophagitis in patients with AIDS. A clinical, endoscopic, and pathologic correlation. Ann Intern Med 113: 589-593

Williams I, Weller IVD, Malin A, Anderson J, Waters RSM (1991) Thalidomide hypersensitivity in AIDS. Lancet 337: 436-437 